\title{
The impact of imposed delay in elective pediatric neurosurgery: an informed hierarchy of need in the time of mass casualty crisis
}

\author{
Ranbir Ahluwalia ${ }^{1,2}$ (D) $\cdot$ Brandon G. Rocque ${ }^{3} \cdot$ Chevis N. Shannon ${ }^{1,4} \cdot$ Jeffrey P. Blount ${ }^{3}$
}

Received: 6 May 2020 / Accepted: 8 May 2020 / Published online: 20 May 2020

(C) Springer-Verlag GmbH Germany, part of Springer Nature 2020

\begin{abstract}
SARS-CoV-2 COVID-19, coronavirus, has created unique challenges for the medical community after national guidelines called for the cancellation of all elective surgery. While there are clear cases of elective surgery (benign cranial cosmetic defect) and emergency surgery (hemorrhage, fracture, trauma, etc.), there is an unchartered middle ground in pediatric neurosurgery. Children, unlike adults, have dynamic anatomy and are still developing neural networks. Delaying seemingly elective surgery can affect a child's already vulnerable health state by further impacting their neurocognitive development, neurologic functioning, and potential long-term health states. The purpose of this paper is to demonstrate that "elective" pediatric neurosurgery should be risk-stratified, and multi-institutional informed guidelines established.
\end{abstract}

Keywords SARS-CoV-2 COVID-19 · COVID-19 · Coronavirus · Craniosynostosis · Brachial plexus $\cdot$ Pediatric neurosurgery

\section{Introduction}

The COVID-19 pandemic has created unique challenges for pediatric neurosurgeons. Elective procedures have been postponed at virtually all major pediatric neurosurgery centers. While there has been some centralized effort in adult surgery to standardize and stratify low vs. high acuity [1], this has not yet occurred for pediatric neurosurgery. Given these new restrictions, many fields of medicine have made some general recommendations including head and neck surgery [2], anesthesia [3], cardiac

Previous presentations: This abstract has not been previously presented.

Ranbir Ahluwalia

ra16@med.fsu.edu

1 Surgical Outcomes Center for Kids, Monroe Carell Jr. Children's Hospital at Vanderbilt, Nashville, TN, USA

2 Florida State University College of Medicine, 1115 W Call St., Tallahassee, FL 32304, USA

3 Department of Neurosurgery, University of Alabama at Birmingham, Children's of Alabama, Birmingham, AL, USA

4 Department of Neurological Surgery, Vanderbilt University Medical Center, Nashville, TN, USA electrophysiology [4], and colorectal surgery [5]. While some recommendations apply to neurosurgery, particularly endoscopic sinonasal and skull base recommendations [2], no manuscripts exist to systematically stratify risk associated with delay in common pediatric neurosurgical procedures.

The purpose of this paper is to outline the risks associated with delaying elective pediatric neurosurgery. Urgent cases that present an immediate threat to the patient's life or neurologic well-being (e.g., shunt malfunction, acute hematoma evacuation, tumor with hydrocephalus, empyema, spinal cord compression) are straightforward and undergo prompt surgical intervention. Elective surgery is readily defined as cases that offer a negligible or minimal threat of harm to the patient if surgery is delayed for several months. Examples might include skull dermoids/epidermoids, prophylactic spinal lipoma untethering operations, and some craniofacial procedures. These are similarly less challenging in the current environment. However, there are a large number of procedures which are less straightforward in which lack of prompt surgery, while not emergent, may result in neurologic harm to the patient. Delaying all "elective" surgeries in this population poses health-related risks, and a review of best available evidence on harm imposed by delaying these operations is warranted. 


\section{Methods}

The authors have identified a sample of pediatric neurosurgery procedures that are neither clearly emergent nor purely elective. Cases considered for review include the following diagnoses/scenarios:

1. Tumor recurrence without hydrocephalus

2. Chiari I malformation

3. Medically resistant epilepsy

4. Craniosynostosis-single suture and syndromic multisuture synostosis

5. Tethered spinal cord

6. Brachial plexus

7. Moyamoya disease

A PubMed-based literature survey was conducted for manuscripts that addressed morbidity arising from delay in intervention for these diagnoses. Manuscripts were prioritized on the basis of relevance of study design and evidence quality and were excluded for the following reasons: opinion paper, review paper, single case report, lack of outcomes results, or pertaining to the adult population. Papers that presented outcomes from delayed surgery were included in this review.

1. Tumor recurrence without hydrocephalus or symptoms of mass effect (i.e., purely radiographic recurrence):

i. Issues/threats with surgical delay:

(a) Sudden decline from hemorrhage into tumor or acute development of hydrocephalus

(b) Risks of dissemination or de-differentiation into higher grade lesion.

Supporting evidence Low-grade neoplasms characteristically show slow, linear growth with a minimal risk of rapid decline from mass effect [6]. For pilocytic astrocytomas, the greatest risk is likely the development of a cystic component that may show focal accelerated growth [7]. Other lesions such as craniopharyngiomas show highly variable growth patterns and often have a cystic component that may expand more rapidly to cause mass effect or obstruction [8]. Another important consideration in predicting potential risk for focal mass effect is the degree of surrounding edema elicited by the tumor. This risk also correlates with tumor histology [9]. Low-grade tumors such as pilocytic astrocytomas, glioneuronal tumors (DNT, ganglioglioma, etc.) and grade I gliomas typically offer a low risk for acutely developing edema [10]. High-grade pediatric lesions such as PNTs, embryonal tumors, choroid plexus carcinomas, or high-grade gliomas (e.g., glioblastoma multiforme) harbor substantially greater risk for edema and secondary rapid increase in mass effect [10].

Similarly, the incidence of hemorrhage into a tumor recurrence is predominantly determined by histologic diagnosis [11]. The pediatric brain tumors with the highest risk for hemorrhage include high-grade embryonal neoplasms of infancy [12], glioblastoma [13], and mixed malignant germ cell tumors [14]. As such, the prior histology of a recurrent lesion is the principle determinant of the acute risk for a sudden decline from hemorrhage or sudden edema. For example, Donofrio et al. [15] noted thin-walled, small, and closely packed vascularization in pediatric patients with cerebellar hemorrhage from pilocytic astrocytomas 10]. White et al. [16] characterized three distinct histological subtypes which correlated with hemorrhagic events in pilocytic astrocytomas [16]. Specifically, thick-walled hyalinized vessels with glomeruloid structures of vascular endothelial hyperplasia with ectatic vessels serve as a nidus for bleeds [16]. Multiple studies in the literature outline the relationship between histologic features and intratumor hemorrhage [15, 17-20]. Pagano et al. [21] describe recurrent hemorrhage of pilocytic astrocytomas and stressed the importance of VEGF for aberrant neovascularization and hyperpermeability [21]. Immunohistochemistry is now being better understood through genetic markers. As described by Phoenix et al. [41], medulloblastoma genotype highly dictates the vascular environment and hemorrhagic tendencies of tumors [22]. Most recently, Ishi et al. demonstrated the association of FGFR1 mutation with hemorrhagic events in low-grade pediatric gliomas [23].

\section{Chiari malformation with syrinx}

i. Issues/threats with surgical delay:

(a) Neurologic decline in upper extremities from syrinx

(b) Dysesthetic pain from syrinx.

Supporting evidence Chiari I malformation has a range of clinical presentations from headaches to brainstem-related symptoms [24]. When patients are asymptomatic, the clinical course is benign overall $[25,26]$. However, neurologic deficits arising secondary to syringomyelia may not be reversible with surgery. A recent practice preference survey by Rocque et al. [27] of the membership of the American Society of Pediatric Neurosurgery (ASPN) demonstrated a strong preference for using presence of a syrinx regardless of symptoms in the setting of Chiari I malformation as a threshold for surgery [27]. Most surgical series have reported a $60-85 \%$ incidence of syrinx with CIM but larger radiographic series show that only $10-15 \%$ of patients with a C1M have a syrinx $[28,29]$. This 
suggests that patients with syrinxes are selected in surgical series.

Several principles emerge that are helpful in approaching the dilemma of acceptable delay challenge for an asymptomatic patient with a C1M-related syrinx:

(1) The onset of neurologic symptoms from a C1M syrinx is usually insidious and gradual but can rarely be acute [30]. Only a limited number of papers address acute decline from C1M related syringomyelia [28, 31-34]. Massimmi [35] and colleagues identified 3 patients in their center experience and then identified 38 more patients from the literature that showed acute clinical decline [35]. They concluded in 2012 that only 41 of such patients had ever been identified and concluded that sudden presentation is extremely rare [35]. However, morbidity (irreversible motor 37\%, 29\% respiratory failure) and mortality $(20 \% ; 14.5 \%$ cardiac arrest) were severe when it did occur [35].

Almotairi and colleagues [36] observed 3 patients to acutely decline in a cohort of $65(3 / 65=4.6 \%)$ adult patients from Sweden who were followed and treated for C1M-related syrinx [36]. In this series, the patients that declined acutely demonstrated longer and wider syrinxes that extended more rostrally (above $\mathrm{C} 1$ ) than the larger group who demonstrated no acute decline [36]. The extent of tonsillar herniation did not correlate [36].

(2) The response time of a syrinx to operative decompression is unknown and appears gradual. Wetjen and Oldfield [37] studied 29 patients who underwent posterior fossa decompression for $\mathrm{C} 1 \mathrm{M}$ and found a median time of 3.6 months $(95 \% \mathrm{CI}=3.0-6.5$ months) [37]. Experienced Chiari surgeons typically advocate MRI imaging follow-up in 6-12 months.

(3) Surgical decompression has a consistently good but variable impact on syrinx. Tubbs et al. [29] found that only 4 out of 285 patients with syrinx demonstrated progression after posterior fossa decompression and cranioplasty [29]. Zhang and colleagues [38] demonstrated that $60 \%$ of patients who underwent posterior fossa decompression with duraplasty showed a reduction in size. Less is written or available on the time course of syrinx change and the common time point for observations is 6 months. A large meta-analysis by Durham and Fjeld-Olenec [39] that compared techniques of $\mathrm{C} 1 \mathrm{M}$ decompression (decompression alone vs. decompression with duraplasty) demonstrated 56-87\% syrinx resolution with operative decompression [39]. However, small numbers of syrinxes associated with Chiari I decrease in size over time without operative intervention and some syrinxes do not change after posterior fossa.

(4) Recovery of neurologic symptoms from a Chiari related syrinx is typically incomplete and permanent. The presence of a syrinx then represents a non-predictable risk factor for irreversible neurologic dysfunction from intrinsic chronic stress and injury to the spinal cord. Sudden decline is very rare but can occur especially from minor injury [28, 31-34].

Thus, it appears that there is a strong preference by experienced pediatric neurosurgeons to intervene for a syrinx associated with a $\mathrm{C} 1 \mathrm{M}$ but the supporting evidence is incomplete and imperfect. The presence of the syrinx represents a threat to stress and low-grade chronic injury to the cord. It is very uncommon for acute symptoms to develop and the response to treatment usually occurs over months. Therefore, a modest delay appears of low risk but the presence of a syrinx appears to be a justifiable intervention in an environment of imposed surgical slow down due to rare but possible neurologic insult that is permanent.

\section{Medically resistant epilepsy}

By convention, only children with medically resistant epilepsy (MRE) are candidates for epilepsy surgery and most epilepsy surgery can be elective. There are however important criteria within the designation of MRE that help stratify patients with regard to the risk associated with operative delay. These include the risk for sudden death in epilepsy (SUDEP), the frequency and severity of status epilepticus (including status epilepticus in sleep or ESES), the overall seizure burden for the child, and the degree of medical resistance that the seizures demonstrate.

Issues/threats with surgical delay:

(a) Acute threat of catastrophic epilepsy: sudden death in epilepsy (SUDEP), non-reversible injury to the brain from status epilepticus, and ESES

(b) Sub-acute/chronic impact of uncontrolled seizures: the adverse effects to normal neurologic development from prolonged seizures

(c) Presence of a lesion (e.g., tumor, cavernomas)

(d) Palliative interventions: e.g., vagus nerve stimulator implantation.

\section{Supporting evidence}

Medical resistance/acute threats of MRE Defining and characterizing medical resistance (MRE): Candidacy for epilepsy surgery hinges upon defining medical resistance as a failure of 2 anti-epileptic medications at proper dose to confer control of seizures. Approximately one-third of patients with epilepsy will demonstrate MRE. These patients are candidates for surgical intervention and the overwhelming majority can be 
evaluated and operated upon electively. However, an increased percentage of children have catastrophic epilepsy which is characterized by highly resistant and threatening generalized seizures. These often culminate in repeated episodes of status epilepticus and raise the risk for sudden death in epilepsy (SUDEP). Children with congenital or acquired structural anomalies of the brain such as hemimegalencephaly, holohemispheric dysplasias, hemispheric atrophy, and cystic encephalomalacia (often due to perinatal infarcts/ischemia) are more frequently found to have catastrophic epilepsy than those patients with more normal MRI findings. Syndromic epilepsies such as Lennox-Gastaut and Rasmussen's encephalitis are highly resistant and associated with progressively severe and difficult to control disease.

Similarly recurring episodes of status epilepticus, Epilepsia partialis continua, or electrical status epilepticus in sleep (ESES) threaten the child's safety and neurologic development. Children with malignant, threatening patterns such as these warrant an assertive, proactive approach to control and localization of their seizures. When accompanied by a structural change, these epilepsies are typically focal in onset and are amenable to surgical resection. Due to the acute risk and lack of other effective strategies, surgery for these cases is often considered urgent and is justifiable and appropriate to proceed to surgery in an environment in which elective cases are suspended.

\section{Threat to cognition and neurocognitive development}

There remains little doubt that uncontrolled epilepsy in children is injurious to the developing brain and adversely impacts normal neurocognitive development. The timing of epilepsy surgery is critical to achieve optimal long-term neurocognitive benefit. A retrospective study conducted by Jenny et al. [40] demonstrated higher seizure-free rate in infants $(89.5 \%)$ vs. children (72.9\%) [40]. Additionally, binary logistic regression demonstrated that younger children (less than 3 years of age) were 2.76 times more likely to achieve a seizure-free outcome compared with older children (4 to 17 years of age) [40]. Furthermore, developmental outcome as assessed by Loddenkemper et al. [41] using Bayley Scales of Infant Development demonstrated that younger age at time of epilepsy surgery was correlated with a higher improvement in the development quotient (correlation coefficient $0.72, p<0.001$ ) [41]. Finally, Pelliccia et al. [42] performed multivariate analysis using stepwise logistic regression to determine factors associated with seizure freedom and found a shorter duration of epilepsy to be significant (OR 0.92, 95\% CI 0.89-0.94; $p<0.001$ ) [42].

\section{Lesional epilepsy}

Lesional epilepsy represents a unique situation with regard to surgical decision-making. There are often 2 indications for intervention: (1) removal and histologic diagnosis of the lesion and (2) improved seizure control. The presence of a visible lesion in the region implicated by EEG and functional imaging to be epileptogenic markedly increases the likelihood of successful surgery. The most common etiologies for lesional epilepsies in children are ganglioneuronal tumors, cavernomas, and visible cortical dysplasias.

Gangliogliomas (GGs) and dysembryoplastic neuroepithelial tumors (DNETs) are low-grade brain tumors that commonly present with seizures. Seizure-freedom in this group of children is critical. As demonstrated by Englot et al. [43], seizure freedom is achieved with higher success in children less than or equal to 1 year of life compared with those greater than 1 year of age (OR 9.48; 95\% CI, 2.26-39.66). Nolan et al. [44] performed a univariate chi-squared analysis to determine factors influencing favorable prognosis in children with DNTs and found shorter duration of epilepsy ( $p=$ $0.01)$ and younger age at surgery $(p=0.04)$ to be significant [44]. Finally, when evaluating cognitive outcomes, earlier surgery for tumor-related epilepsy is ideal. Ramantani et al. [45] conducted a retrospective review in children with glioneuronal tumors to determine factors that influenced cognitive outcomes. Lower full-scale IQ (FSIQ) and verbal IQ (VQ) were related to longer duration between diagnosis and surgery, when controlled for age at epilepsy onset (FSIQ $r=$ 20.537, $\mathrm{df}=22, p=0.007$; VIQ $r=20.504, \mathrm{df}=17, p=0.028$ ) [45].

The nearly uniform good outcomes from lesional resections for epilepsy along with a need for histopathologic diagnosis in many cases make a convincing case for proceeding to surgery even in the presence of initiatives to limit elective cases.

4. Craniosynostosis-single suture non-syndromic synostosis

(1) Issues/threats with surgical delay:

ii. Candidacy for endoscopic techniques - typically endoscopic preferred less than 12 months

iii. Capacity for bony defects to fill in declines with age

iv. Thicker bone is more rigid and offers greater technical challenges with more bleeding, higher morbidity, and associated longer stay and higher cost.

(2) Supporting evidence:

Endoscopic techniques in craniofacial surgery are being increasingly utilized due to good outcomes, lower morbidity, costs, blood loss, and equivalent or superior aesthetic outcomes. As demonstrated by Thompson et al. [46], endoscopic treatment utilizes less blood (26\% vs. $81 \%, p<0.001$ ), coagulation products (3\% vs. $16 \%, p<$ 0.001 ), anesthesia (168 vs. $248 \mathrm{~min} \%, p<0.001$ ), surgical duration (70 vs. $130 \mathrm{~min} \%, p<0.001)$, days in ICU (0 vs. $2 \%, p<0.001)$, and hospital LOS ( 2 vs. $4 \%, p<0.001)$ 
[46]. However, if a child is not seen within an appropriate timeframe, endoscopic craniosynostosis repair is no longer possible. While there remains debate about the superiority of endoscopic versus open repair, it is clear that in older children, only open repair can be performed.

As the skull matures, the capacity for spontaneous filling in of bony defects or gaps between bone grafts becomes reduced. Under the age of 18 months, the gaps between bone grafts are largely filled with fibrous tissue and islands of cartilage. The capacity to spontaneously fill and remodel bony defects dissipates with increasing age resulting in less satisfactory results in older children.

A retrospective study spanning 6 years, 44 states, and 8417 children under the age of 3 was conducted by Bruce et al. [47] to determine the optimal time to surgically repair craniosynostosis. Using the Healthcare Cost and Utilization Project Kids' inpatient database (KID), the overall complication rate was $8.6 \%$ : $6.6 \%$ for children aged 0 to 6 months, $10.3 \%$ for patients aged 7 to 12 months, and $13.9 \%$ in children aged 12 to 36 months [47]. Additionally, a multivariable logistic regression model to identify factors that increase perioperative surgical complication demonstrated age as a significant factor $(\mathrm{OR}=2.53$ at 3 years vs. $<1,95 \%$ CI 1.67-3.82) [47]. Another study using the KID database showed delayed repair of craniosynostosis to be associated with longer length of stay (LOS) and increased cost [48]. In a sample of 3246 patients with an average age of 181 days, LOS directly impact mean charge and total cost [48]. When creating a regression model for factors that significantly impacted the length of stay, age was the most significant [48]. Older aged children had up to a three times greater odds of a longer LOS [48].

\section{Syndromic multi-suture synostosis (e.g., Apert, Crouzon,} Saethre-Chotzen, or Cloverleaf deformity): Multiple suture synostoses can give rise to brain constriction and elevated intra-cranial pressure that can be threatening to brain growth and optic nerve function. In the syndromic cases, the characteristic brachycephaly requires bi-frontal orbital advancement or distraction. The skull characteristically can be molded and reossification occurs readily until about the age of 2 years. After this, the bone is thicker, more brittle, and does not contour as readily. Consequently, there is likely limited harm in delaying syndromic cases inside of 2 years of age. Treatment of midface hypoplasia occurs in mid-childhood via distraction or LeFort midface advancement procedures.

\section{Tethered spinal cord}

The tethered cord syndrome (TCS) may arise from a variety of pathologic entities that share the capacity to fix the spinal cord to surrounding mesenchymal structures (e.g., bony spine or surrounding muscle and connective tissues) [49]. Symptoms usually consist of pain in the back, buttocks, and legs and variable but progressive loss of neurologic function in the legs and bladder [49]. Prevailing wisdom in pediatric neurosurgery is that once function is lost, it is typically not regained. Thus, the critical immediate distinction in tethered cord is between symptomatic and asymptomatic tethered cord. Intervention for asymptomatic tethered cord is largely prophylactic and is variably controversial depending on the underlying tethering lesion. For example, split cord malformations have a high incidence of inducing progressive neurologic decline unless repaired whereas the natural history of a low-lying spinal conus medullaris is less well established and there is significant controversy surrounding prophylactic untethering.

The fundamental question is the likelihood that delay in surgery may impart a decline in neurological function. Koyangi et al. [50] retrospectively described the efficacy of surgery given the natural history of tethered cord syndrome. Post-operatively, 7/8 (88\%) asymptomatic patients remained this way, 6/26 (23\%) improved, and 15/26 (58\%) patients were unchanged [50]. Hoffman et al. [51] describe a similar relationship in a cohort of 97 pediatric patients. Fifty-six patients presented before the age of 6 months, and 35 of these patients were neurologically intact [51]. However, of the 41 patients presenting after the age of 6 months, only 12 patients were neurologically intact [51]. Surgery should be performed prior to the onset of neurologic deficits. As demonstrated by Kanev et al. [52] in a cohort of 42 patients presenting with neurologic deficit, $0 / 42(0 \%)$ of patients regained bladder or bowel function post-operatively [52]. A logarithmic model developed by Kanev et al. using data from two series [51, 52] demonstrates that all patients would develop neurological deficits over time by 12 years of age [53]. While these studies do not provide definitive evidence of a danger with delay, they do suggest that prevention of deficit or worsening of deficits might be more successful with earlier surgery.

\section{Obstetrical brachial plexus injury}

Prompt neurosurgical evaluation is necessary to determine the level of the lesion and distribution of neurological injury [54]. While the most common presentation is that of an upper plexus injury (Erb's palsy) with damage occurring to the C5 and C6 roots [54], the most serious lesion is a total plexus lesion, which involves $\mathrm{C} 5, \mathrm{C} 6, \mathrm{C} 7$, and $\mathrm{C} 8$, with or without T1 [54]. The patient will present with a flail limb and possibly Horner's syndrome [54]. Prevailing opinion among surgeons from multiple disciplines is that these children require urgent exploration of the brachial plexus with appropriate nerve grafts and transfers [54].

For patients with an Erb's palsy, upper plexus, and pattern of lesion, there are multiple competing studies of various 
quality regarding the ideal time of surgery [55-57]. A recent multicenter study [58] evaluated microsurgical outcomes in children who underwent plexus reconstruction before versus after 6 months of age. In the multivariable model, accounting for Horner syndrome and baseline Toronto score, there was no statistical difference in outcome between the early and late surgery (AMS score difference $=0.6,95 \% \mathrm{CI}=-8.0$ to 9.3 , $p=0.88)$ [58].

In sharp contrast, total obstetric brachial plexus palsy injury requires more prompt surgical treatment and should ideally be performed around 3 months of age [59]. In a cohort of 35 patients with total obstetric brachial palsy injury, younger age at the time of surgery correlated with better functional recovery $(r=-0.356, p=0.049)$, particularly with finger and thumb flexion [59].

\section{Discussion}

The onset of COVID-19 and the national guidance to delay elective surgery has changed the paradigms of operative pediatric neurosurgical practice. The need for social distancing and preservation, or limited availability, of personal protective equipment has resulted in widespread curtailment of elective operative procedures. During this time, it is essential to establish an informed hierarchy of need for pediatric neurosurgical cases. Many pediatric neurosurgery cases are urgent and must proceed. Examples include shunt obstructions, infections, post-traumatic hematomas, and myelomeningocele closures. Other cases are clearly elective and results are not likely impacted by limited delays. However, there exist a significant number of pediatric neurosurgical cases for which the impact of time delay in intervention is unknown. Some cases appear elective but review of published experience demonstrates that poorer outcomes or higher risk accompanies delay. An informed hierarchy of need incorporates the potential increase into adverse outcomes associated with delay as well as the imminent threat to the patient in the short term. The cases selected for this report are not comprehensive but are representative of a substantial component of elective pediatric neurosurgical practice. Within these cases, there are multiple examples of how a delay in performing surgery during an optimal eligibility window is associated with more adverse effects over the life span.

Additional factors that should be considered include the potential for exposure of risk to the operative team. Exposure risks not only center on airway control and intubation but also extend to risks associated with aerosolized particles including blood, CSF, and bone. Cases involving invasion into the airways and bony sinuses also carry elevated risks. Examples would include anterior skull base procedures, craniofacial procedures, and evacuation of empyemas that arise from erosion through bony sinuses.
Presurgical COVID19 screening should be implemented in areas where there is no current shortage of testing for symptomatic patients. If limited testing is available, cases in which exposure is gained endonasally should require preoperative COVID19 screening.

Ultimately, ideal timing should be explored for all pediatric neurosurgery. However, an effort that exhaustive is outside the scope of this manuscript's purpose of creating awareness on delay of common pediatric neurosurgical procedures. For the sake of completeness, some basic recommendations can be made regarding the procedures listed. For example, craniosynostosis repair should not exceed 4 months to prevent open surgery. Total obstetrical brachial plexus repair should be performed by 3 months of age to prevent neurologic deficit. Additionally, asymptomatic tethered cord and Chiari I malformation with syrinx should not be postponed longer than 6 months as the purpose of surgery is symptom prophylaxis. Lesional epilepsy represents a more complex disease process and a case-by-case evaluation is necessary depending on seizure burden, medication use, and concurrent tumor. As the referenced literature demonstrates, there are clear transition points in childhood ( 1 year of age and 3 years of age) that represent important checkpoints for intervention.

In sum, there are multiple levels of consideration when properly assessing the timing of surgery. Imminent danger to the patient is foremost but the potential for adverse outcomes from missing an optimal time window of eligibility should also be considered. This review has demonstrated multiple examples of common pediatric neurosurgical procedures where such phenomena are observed. Finally, considerations of operative team exposure and resource utilization need to be considered.

\section{Conclusion}

Proper evaluation of the timing of a pediatric neurosurgery case must extend beyond the period of an imminent threat to the patient. Evaluation of a representative sample of pediatric neurosurgical cases demonstrates how adverse outcomes arise consistently when important optimum time windows of candidacy are missed. In addition, exposure risk and resource consumption in an era of scarcity must be considered to attain the best overall decision regarding the timing of pediatric neurosurgical intervention.

\section{Compliance with ethical standards}

Conflict of interest The other authors report no conflict of interest concerning the materials or methods used in this study or the findings specified in this paper. The authors have no personal or institutional financial interest in drugs, materials, or devices described in their submissions. 


\section{References}

1. Siddiqui S (2020) COVID-19: Guidance for triage of non-emergent surgical procedures. American College of Surgeons

2. Givi B, Schiff BA, Chinn SB, Clayburgh D, Iyer NG, Jalisi S, Moore MG, Nathan C-A, Orloff LA, O'Neill JP, Parker N, Zender C, Morris LGT, Davies L (2020) Safety recommendations for evaluation and surgery of the head and neck during the COVID19 pandemic. JAMA Otolaryngology-Head \& Neck Surgery. https://doi.org/10.1001/jamaoto.2020.0780

3. Wen X, Li Y (2020) Anesthesia Procedure of emergency operation for patients with suspected or confirmed COVID-19. Surgical infections 21:299. https://doi.org/10.1089/sur.2020.040

4. Lakkireddy DR, Chung MK, Gopinathannair R, Patton KK, Gluckman TJ, Turagam M, Cheung J, Patel P, Sotomonte J, Lampert R, Han JK, Rajagopalan B, Eckhardt L, Joglar J, Sandau K, Olshansky B, Wan E, Noseworthy PA, Leal M, Kaufman E, Gutierrez A, Marine JM, Wang PJ, Russo AM (2020) Guidance for cardiac electrophysiology during the coronavirus (COVID-19) pandemic from the Heart Rhythm Society COVID-19 Task Force; Electrophysiology Section of the American College of Cardiology; and the Electrocardiography and Arrhythmias Committee of the Council on Clinical Cardiology. American Heart Association. Heart Rhythm. https://doi.org/10.1016/j.hrthm. 2020.03.028

5. Di Saverio S, Pata F, Gallo G, Carrano F, Scorza A, Sileri P, Smart N, Spinelli A, Pellino G Coronavirus pandemic and Colorectal surgery: practical advice based on the Italian experience. Colorectal Disease n/a. doi:https://doi.org/10.1111/codi.15056, 2020

6. de Blank P, Bandopadhayay P, Haas-Kogan D, Fouladi M, Fangusaro J (2019) Management of pediatric low-grade glioma. Curr Opin Pediatr 31:21-27. https://doi.org/10.1097/MOP. 0000000000000717

7. Collins VP, Jones DTW, Giannini C (2015) Pilocytic astrocytoma: pathology, molecular mechanisms and markers. Acta Neuropathol 129:775-788. https://doi.org/10.1007/s00401-015-1410-7

8. Graffeo CS, Perry A, Link MJ, Daniels DJ (2018) Pediatric Craniopharyngiomas: a primer for the skull base surgeon. J Neurol Surg B Skull Base 79:65-80. https://doi.org/10.1055/s0037-1621738

9. Pfister S, Hartmann C, Korshunov A (2009) Histology and molecular pathology of pediatric brain tumors. J Child Neurol 24:13751386. https://doi.org/10.1177/0883073809339213

10. Sturm D, Pfister SM, Jones DTW (2017) Pediatric gliomas: current concepts on diagnosis, biology, and clinical management. Journal of clinical oncology : official journal of the American Society of Clinical Oncology 35:2370-2377. https://doi.org/10.1200/jco. 2017.73.0242

11. Kondziolka D, Bernstein M, Resch L, Tator CH, Fleming JF, Vanderlinden RG, Schutz H (1987) Significance of hemorrhage into brain tumors: clinicopathological study. Journal of neurosurgery 67:852-857. https://doi.org/10.3171/jns.1987.67.6.0852

12. MacDonald TJ (2008) Aggressive infantile embryonal tumors. Journal of child neurology 23:1195-1204. https://doi.org/10.1177/ 0883073808321769

13. Licata B, Turazzi S (2003) Bleeding cerebral neoplasms with symptomatic hematoma. Journal of neurosurgical sciences 47:201-210 discussion 210

14. Kishore M, Monappa V, Rao L, Kudva R (2014) Mixed malignant germ cell tumour of third ventricle with hydrocephalus: a rare case with recurrence. J Clin Diagn Res 8:FD03-FD05. https://doi.org/ 10.7860/JCDR/2014/9866.5124

15. Donofrio CA, Gagliardi F, Callea M, da Passano CF, Terreni MR, Cavalli A, Spina A, Acerno S, Bailo M, Elbabaa SK, Mortini P
(2020) Pediatric cerebellar pilocytic astrocytoma presenting with spontaneous intratumoral hemorrhage. Neurosurgical review 43: 9-16. https://doi.org/10.1007/s10143-018-0969-6

16. White JB, Piepgras DG, Scheithauer BW, Parisi JE (2008) Rate of spontaneous hemorrhage in histologically proven cases of pilocytic astrocytoma. Journal of neurosurgery 108:223-226. https://doi.org/ $10.3171 /$ jns $/ 2008 / 108 / 2 / 0223$

17. Kalina P (2012) Pediatric cerebellar hemorrhagic glioblastoma multiforme. Open Neuroimag J 6:13-15. https://doi.org/10.2174/ 1874440001206010013

18. Mesiwala AH, Avellino AM, Roberts TS, Ellenbogen RG (2001) Spontaneous cerebellar hemorrhage due to a juvenile pilocytic astrocytoma: case report and review of the literature. Pediatric neurosurgery 34:235-238. https://doi.org/10.1159/000056028

19. Mitchell PW, Edward SJ, Cynthia H, Kerry A, Wael A, Jeffrey AP (2016) Hemorrhagic presentations of cerebellar pilocytic astrocytomas in children resulting in death: report of 2 cases. Journal of Neurosurgery: Pediatrics PED 17:446-452. https://doi.org/10. 3171/2015.10.PEDS1580

20. Specht CS, Pinto-Lord C, Smith TW, DeGirolami U, Suran E, Marshall PC, Davidson RI (1986) Spontaneous hemorrhage in a mixed glioma of the cerebellum: case report. Neurosurgery 19: 278-281. https://doi.org/10.1227/00006123-198608000-00019

21. Pagano A, Novegno F, Ferlosio A, Lunardi P (2019) Repeat bleeding 18 years after hemorrhagic pilocytic astrocytoma: prognostic implications of conservative management-case report and literature review. World neurosurgery 123:328-338. https://doi.org/10.1016/ j.wneu.2018.12.032

22. Phoenix TN, Patmore DM, Boop S, Boulos N, Jacus MO, Patel YT, Roussel MF, Finkelstein D, Goumnerova L, Perreault S, Wadhwa E, Cho Y-J, Stewart CF, Gilbertson RJ (2016) Medulloblastoma genotype dictates blood brain barrier phenotype. Cancer Cell 29: 508-522. https://doi.org/10.1016/j.ccell.2016.03.002

23. Ishi Y, Yamaguchi S, Hatanaka KC, Okamoto M, Motegi H, Kobayashi H, Terasaka S, Houkin K (2020) Association of the FGFR1 mutation with spontaneous hemorrhage in low-grade gliomas in pediatric and young adult patients. Journal of neurosurgery: 1-9. https://doi.org/10.3171/2019.12.Jns192155

24. Alexander H, Tsering D, Myseros JS, Magge SN, Oluigbo C, Sanchez CE, Keating RF (2019) Management of Chiari I malformations: a paradigm in evolution. Child's nervous system : ChNS : official journal of the International Society for Pediatric Neurosurgery 35:1809-1826. https://doi.org/10.1007/s00381-019$04265-2$

25. Leon TJ, Kuhn EN, Arynchyna AA, Smith BP, Tubbs RS, Johnston JM, Blount JP, Rozzelle CJ, Oakes WJ, Rocque BG (2019) Patients with "benign" Chiari I malformations require surgical decompression at a low rate. Journal of neurosurgery Pediatrics 23:498-506. https://doi.org/10.3171/2018.10.Peds18407

26. Strahle J, Muraszko KM, Kapurch J, Bapuraj JR, Garton HJ, Maher CO (2011) Natural history of Chiari malformation Type I following decision for conservative treatment. Journal of neurosurgery Pediatrics 8:214-221. https://doi.org/10.3171/2011.5.Peds1122

27. Rocque BG, George TM, Kestle J, Iskandar BJ (2011) Treatment practices for Chiari malformation type I with syringomyelia: results of a survey of the American Society of Pediatric Neurosurgeons. J Neurosurg Pediatr 8:430-437. https://doi.org/10.3171/2011.8. Peds 10427

28. Milhorat TH, Bolognese PA, Black KS, Woldenberg RF (2003) Acute syringomyelia: case report. Neurosurgery 53:1220-1221; discussion 1221-1222. https://doi.org/10.1227/01.neu. 0000088809.14965.00

29. Tubbs RS, Joshua B, Robert PN, Joshua JC, John CW, Curtis JR, Jeffrey PB, Oakes WJ (2011) Institutional experience with 500 cases of surgically treated pediatric Chiari malformation Type I. 
Journal of Neurosurgery: Pediatrics PED 7:248-256. https://doi. org/10.3171/2010.12.PEDS10379

30. Anwer UE, Fisher M (1996) Acute and atypical presentations of syringomyelia. European neurology 36:215-218. https://doi.org/ 10.1159/000117251

31. Miranda SP, Kimmell KT, Silberstein HJ (2016) Acute presentation of Chiari I malformation with hemiparesis in a pediatric patient. World neurosurgery 85(366):e361-e364. https://doi.org/10.1016/j. wneu.2015.09.003

32. Talamonti G, Marcati E, Gribaudi G, Picano M, D'Aliberti G (2020) Acute presentation of Chiari 1 malformation in children. Childs Nerv Syst 36:899-909. https://doi.org/10.1007/s00381020-04540-7

33. Tsara V, Serasli E, Kimiskidis V, Papagianopoulos S, Katsaridis V, Fylaktakis M, Christaki P, Kazis A (2005) Acute respiratory failure and sleep-disordered breathing in Arnold-Chiari malformation. Clinical neurology and neurosurgery 107:521-524. https://doi.org/ 10.1016/j.clineuro.2004.10.008

34. Yarbrough CK, Powers AK, Park TS, Leonard JR, Limbrick DD, Smyth MD (2011) Patients with Chiari malformation type I presenting with acute neurological deficits: case series. Journal of neurosurgery Pediatrics 7:244-247. https://doi.org/10.3171/2010.11. Peds1097

35. Massimi L, Della Pepa GM, Caldarelli M, Di Rocco C (2012) Abrupt clinical onset of Chiari type I/syringomyelia complex: clinical and physiopathological implications. Neurosurgical review 35: 321-329; discussion 329. https://doi.org/10.1007/s10143-0120391-4

36. Almotairi FS, Tisell M (2020) Acute deterioration of adults with Chiari I malformation associated with extensive syrinx. British journal of neurosurgery 34:13-17. https://doi.org/10.1080/ 02688697.2019 .1684438

37. Wetjen NM, Heiss JD, Oldfield EH (2008) Time course of syringomyelia resolution following decompression of Chiari malformation Type I. Journal of neurosurgery Pediatrics 1:118-123. https:// doi.org/10.3171/ped/2008/1/2/118

38. Zhang ZQ, Chen YQ, Chen YA, Wu X, Wang YB, Li XG (2008) Chiari I malformation associated with syringomyelia: a retrospective study of 316 surgically treated patients. Spinal cord 46:358363. https://doi.org/10.1038/sj.sc.3102141

39. Durham SR, Fjeld-Olenec K (2008) Comparison of posterior fossa decompression with and without duraplasty for the surgical treatment of Chiari malformation Type I in pediatric patients: a metaanalysis. Journal of neurosurgery Pediatrics 2:42-49. https://doi. org/10.3171/ped/2008/2/7/042

40. Jenny B, Smoll N, El Hassani Y, Momjian S, Pollo C, Korff CM, Seeck M, Schaller K (2016) Pediatric epilepsy surgery: could age be a predictor of outcomes? Journal of neurosurgery Pediatrics 18: 235-241. https://doi.org/10.3171/2015.10.Peds14413

41. Loddenkemper T, Holland KD, Stanford LD, Kotagal P, Bingaman W, Wyllie E (2007) Developmental outcome after epilepsy surgery in infancy. Pediatrics 119:930-935. https://doi.org/10.1542/peds. 2006-2530

42. Pelliccia V, Deleo F, Gozzo F, Sartori I, Mai R, Cossu M, Tassi L (2017) Early and late epilepsy surgery in focal epilepsies associated with long-term epilepsy-associated tumors. Journal of neurosurgery 127:1147-1152. https://doi.org/10.3171/2016.9.Jns161176

43. Englot DJ, Berger MS, Barbaro NM, Chang EF (2012) Factors associated with seizure freedom in the surgical resection of glioneuronal tumors. Epilepsia 53:51-57. https://doi.org/10.1111/ j.1528-1167.2011.03269.x

44. Nolan MA, Sakuta R, Chuang N, Otsubo H, Rutka JT, Snead OC 3rd, Hawkins CE, Weiss SK (2004) Dysembryoplastic neuroepithelial tumors in childhood: long-term outcome and prognostic features. Neurology 62:2270-2276. https://doi.org/10.1212/ 01.wnl.0000130495.69512.6f
45. Ramantani G, Kadish NE, Anastasopoulos C, Brandt A, Wagner K, Strobl K, Mayer H, Schubert-Bast S, Stathi A, Korinthenberg R, Feuerstein TJ, Mader I, van Velthoven V, Zentner J, SchulzeBonhage A, Bast T (2014) Epilepsy surgery for glioneuronal tumors in childhood: avoid loss of time. Neurosurgery 74:648-657; discussion 657. https://doi.org/10.1227/neu.0000000000000327

46. Thompson DR, Zurakowski D, Haberkern CM, Stricker PA, Meier PM, Bannister C, Benzon H, Binstock W, Bosenberg A, Brzenski A, Budac S, Busso V, Capehart S, Chiao F, Cladis F, Collins M, Cusick J, Dabek R, Dalesio N, Falcon R, Fernandez A, Fernandez P, Fiadjoe J, Gangadharan M, Gentry K, Glover C, Goobie S, Gries H, Griffin A, Groenewald CB, Hajduk J, Hall R, Hansen J, Hetmaniuk M, Hsieh V, Huang H, Ingelmo P, Ivanova I, Jain R, Koh J, Kowalczyk-Derderian C, Kugler J, Labovsky K, Martinez JL, Mujallid R, Muldowney B, Nguyen KP, Nguyen T, Olutuye O, Soneru C, Petersen T, Poteet-Schwartz K, Reddy S, Reid R, Ricketts K, Rubens D, Skitt R, Sohn L, Staudt S, Sung W, Syed T, Szmuk P, Taicher B, Tetreault L, Watts R, Wong K, Young V, Zamora L (2018) Endoscopic versus open repair for craniosynostosis in infants using propensity score matching to compare outcomes: a multicenter study from the Pediatric Craniofacial Collaborative group. Anesthesia and analgesia 126:968-975. https://doi.org/10.1213/ane.0000000000002454

47. Bruce WJ, Chang V, Joyce CJ, Cobb AN, Maduekwe UI, Patel PA (2018) Age at time of craniosynostosis repair predicts increased complication rate. The Cleft palate-craniofacial journal : official publication of the American Cleft Palate-Craniofacial Association 55:649-654. https://doi.org/10.1177/1055665617725215

48. Nguyen C, Hernandez-Boussard T, Khosla RK, Curtin CM (2013) A national study on craniosynostosis surgical repair. The Cleft palate-craniofacial journal : official publication of the American Cleft Palate-Craniofacial Association 50:555-560. https://doi.org/ 10.1597/11-324

49. Yamada S, Won DJ, Yamada SM (2004) Pathophysiology of tethered cord syndrome: correlation with symptomatology. Neurosurgical focus 16:E6:1-5. https://doi.org/10.3171/foc.2004. 16.2.7

50. Koyanagi I, Iwasaki Y, Hida K, Abe H, Isu T, Akino M (1997) Surgical treatment supposed natural history of the tethered cord with occult spinal dysraphism. Child's nervous system : ChNS : official journal of the International Society for Pediatric Neurosurgery 13:268-274. https://doi.org/10.1007/ s003810050081

51. Hoffman HJ, Taecholarn C, Hendrick EB, Humphreys RP (1985) Management of lipomyelomeningoceles. Experience at the Hospital for Sick Children, Toronto. Journal of neurosurgery 62: 1-8. https://doi.org/10.3171/jns.1985.62.1.0001

52. Kanev PM, Lemire RJ, Loeser JD, Berger MS (1990) Management and long-term follow-up review of children with lipomyelomeningocele, 1952-1987. Journal of neurosurgery 73: 48-52. https://doi.org/10.3171/jns.1990.73.1.0048

53. Kanev PM, Bierbrauer KS (1995) Reflections on the natural history of lipomyelomeningocele. Pediatric neurosurgery 22:137-140. https://doi.org/10.1159/000120891

54. Borschel GH, Clarke HM (2009) Obstetrical brachial plexus palsy. Plastic and reconstructive surgery $124: 144 \mathrm{e}-155 \mathrm{e}$. https://doi.org/ 10.1097/PRS.0b013e3181a80798

55. Hems TEJ, Savaridas T, Sherlock DA (2017) The natural history of recovery of elbow flexion after obstetric brachial plexus injury managed without nerve repair. The Journal of hand surgery, European volume 42:706-709. https://doi.org/10.1177/ 1753193417712924

56. Shenaq SM, Kim JY, Armenta AH, Nath RK, Cheng E, Jedrysiak A (2004) The Surgical treatment of obstetric brachial plexus palsy. Plastic and reconstructive surgery 113:54e-67e. https://doi.org/10. 1097/01.prs.0000110215.61220.72 
57. Waters PM (1999) Comparison of the natural history, the outcome of microsurgical repair, and the outcome of operative reconstruction in brachial plexus birth palsy. The Journal of bone and joint surgery American 81:649-659. https://doi.org/10.2106/00004623199905000-00006

58. Bauer AS, Kalish LA, Adamczyk MJ, Bae DS, Cornwall R, James MA, Lightdale-Miric N, Peljovich AE, Waters PM (2020) Microsurgery for brachial plexus injury before versus after 6 months of age: results of the multicenter Treatment and Outcomes of Brachial Plexus Injury (TOBI) study. The Journal of bone and joint surgery American volume 102:194-204. https://doi.org/10. 2106/jbjs.18.01312

59. El-Gammal TA, El-Sayed A, Kotb MM, Ragheb YF, Saleh WR, Elnakeeb RM, El-Sayed Semaya A (2010) Total obstetric brachial plexus palsy: results and strategy of microsurgical reconstruction. Microsurgery 30:169-178. https://doi.org/10.1002/micr.20726

Publisher's note Springer Nature remains neutral with regard to jurisdictional claims in published maps and institutional affiliations. 